\title{
Monoclonal Antibodies to Uveal Melanoma
}

\author{
B. E. DAMATO, A. M. CAMPBELL,${ }^{*}$ B. J. MCGUIRE, ${ }^{*}$ W. R. LEE and \\ W. S. FOULDS \\ Glasgow
}

\begin{abstract}
Summary
Rat monoclonal antibodies were prepared against antigens expressed by uveal melanomas. Uncultured cells from primary human uveal melanomas were used for the rat inoculations and for the screening of hybridomas by enzyme-linked immunosorbent assay (ELISA). One of the monoclonal antibodies, designated 4A3, recognised a cytoplasmic antigen which was relatively specific for melanoma cells and which could be detected by immunohistochemistry in formalin-fixed, paraffin embedded tumour tissue. Western blotting showed the antigen to have a molecular weight of approximately $55-60 \mathrm{kD}$, with a doublet configuration which showed inter-tumour variation. The antigen was also detected by Western Blotting in the subretinal fluid of patients with uveal melanoma.
\end{abstract}

Knowledge of the antigenic expression of uveal melanomas could be important for further progress in the immunological study of this tumour. With the development of hybridoma technology for the production of monoclonal antibodies, ${ }^{1}$ it is now possible to identify tumour-associated antigens in uveal melanomas and to investigate the extent of their expression in these tumours and in other tissues. Although most monoclonal antibodies to cutaneous melanoma also react with uveal melanoma this is not always the case, suggesting that there are significant antigenic differences between these two types of melanoma. ${ }^{2}$ Rather than adopting monoclonal antibodies previously prepared using cultured cells from cutaneous melanomas, as other workers have done, ${ }^{3}$ our approach has been to prepare monoclonal antibodies using uncultured cells from primary uveal melanomas.

\section{Materials and Methods}

Monoclonal antibodies to uveal melanoma have been raised in the rat and the technique has been described in detail elsewhere (Fig. 1) ${ }^{4}$ In brief, a suspension of melanoma cells was prepared within minutes of the removal of the tumour by local resection or enucleation. The cells were used to coat plastic 96-well plates. They were also used for the immunisation of DA rats. After two or three intraperitoneal inoculations, given at three to four week intervals, the antibody response of the immunised rat was tested by ELISA. ${ }^{5}$ When high levels of serum antibodies to uveal melanomas were demonstrable with this assay (a titre of $1 / 1,000$ or greater), the splenic lymphocytes of the immunised rat were immortalised by fusing them with rat myeloma cells. This was done in a conventional manner: ${ }^{6}$ the two types of cell were centrifuged together; incubated with polyethylene glycol for 90 seconds; and then dispersed into 100 wells for culture. Hypoxanthine-aminopterin-thymidine (HAT) medium was used so that after a week only the hybrid cells had survived. Hybridomas were visible 10-15 days

From the Tennent Institute of Ophthalmology, and the * Department of Biochemistry, University of Glasgow.

Correspondence to: Dr. Bertil E. Damato, FRCS, Tennent Institute of Ophthalmology, University of Glasgow, Glasgow G11 6NT.

Presented at the Annual Congress of the Ophthalmological Society of the United Kingdom, April 1987. 


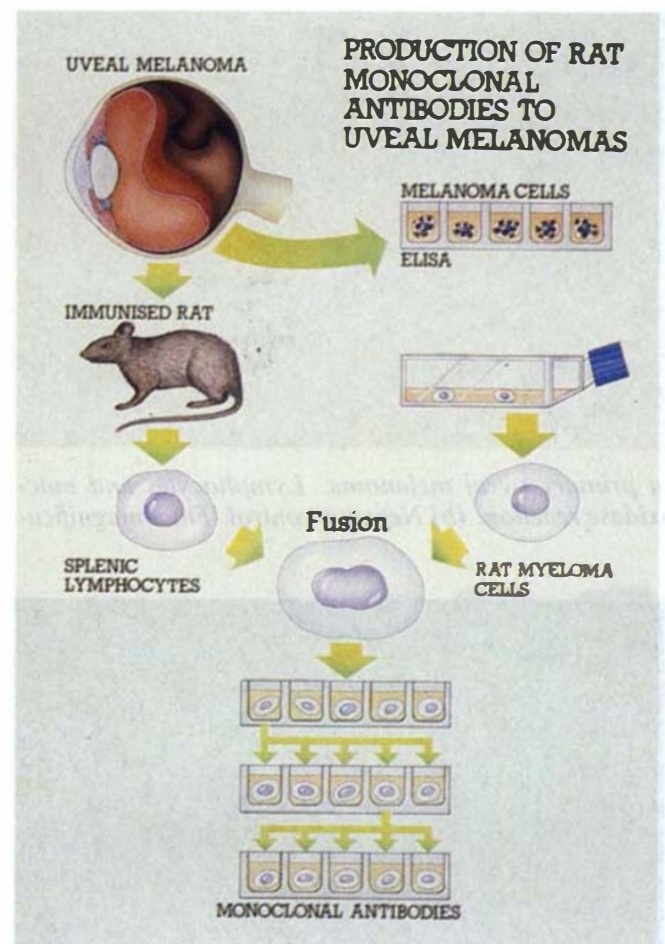

Fig. 1. Strategy used in this study for the production of monoclonal antibodies to uveal melanoma.

after fusion. Those producing antibodies reactive with melanoma cells were detected by ELISA and subcloned at least twice to ensure monoclonality. Bulk cell culture supernatant was concentrated tenfold by precipitation with ammonium sulphate, followed by dialysis into phosphate buffered saline.

The monoclonal antibodies prepared in this study were used to investigate antigens in samples of homogenised uveal melanoma cells and in subretinal fluid. This was done by Western blotting. ${ }^{7}$ In brief, proteins in the sample of uveal melanoma cells were separated according to their molecular weight by SDS-polyacrylamide gel electrophoresis. They were then transferred to nitrocellulose paper by electrophoretic elution so that the relevant antigens could be located by autoradiography following successive incubations with rat monoclonal antibody, rabbit anti-rat immunoglobulin and, finally, ${ }^{125}$ I-labelled protein A. Some of the monoclonal antibodies were further studied by conventional immunohistochemistry, ${ }^{8}$ using paraffin-embedded, formalin-fixed tissue, and by immunofluorescence microscopy using suspensions of melanoma cells. ${ }^{9}$ The class of the antibodies was determined using the Ouchterlony technique. ${ }^{10}$

\section{Results}

To date, more than ten monoclonal antibodies have been produced. Of these, the monoclonal antibody we designated 4A3 was the most interesting. This was an IgM monoclonal antibody which on preliminary screening by ELISA reacted significantly with cells from all 12 uveal melanomas tested and none of six control samples (lymphocytes from five healthy individuals and cells from a breast carcinoma). ${ }^{4}$ These ELISA results were supported by immunohistochemistry which demonstrated staining of the melanoma cells but not the lymphocytes and macrophages within the tumour (Fig. 2). Immunofluorescence microscopy, performed with cultured B008 melanoma cells ${ }^{11}$ showed the $4 \mathrm{~A} 3$ antigen to be intracellular and concentrated in the peri-nuclear region. In contrast, another monoclonal antibody, 4B4-2, stained the cytoskeletal elements in the tumour cells (Fig. 3). Electrophoresis and Western Blotting indicates that the molecular weight of the antigen detected by the 4A3 monoclonal antibody was approximately $55-60 \mathrm{KD}^{4}$ and tended to be expressed as two discrete bands. The appearance of these bands showed intertumour variation (Fig. 4). Using these methods, the 4A3 antigen was demonstrated in the subretinal fluid of patients with uveal melanoma (Fig. 5).

\section{Discussion}

The most important feature of this study is the demonstration that monoclonal antibodies can be produced using uncultured uveal melanoma cells. None of the monoclonal antibodies we produced were entirely specific for an antigen which was present only in melanoma cells. In this respect they are similar to the vast majority of monoclonal antibodies produced against cutaneous melanomas. ${ }^{12}$ There are three main reasons for the lack of absolute specificity of monoclonal antibodies to tumours. Firstly, the antigenic differences between malignant and normal cells are only quantitative, rather than qualitative as previously believed. ${ }^{13}$ Secondly, the methods used for the selection of hybridomas may be inadequate. Despite claims made by other workers, ${ }^{5}$ the ELISA 

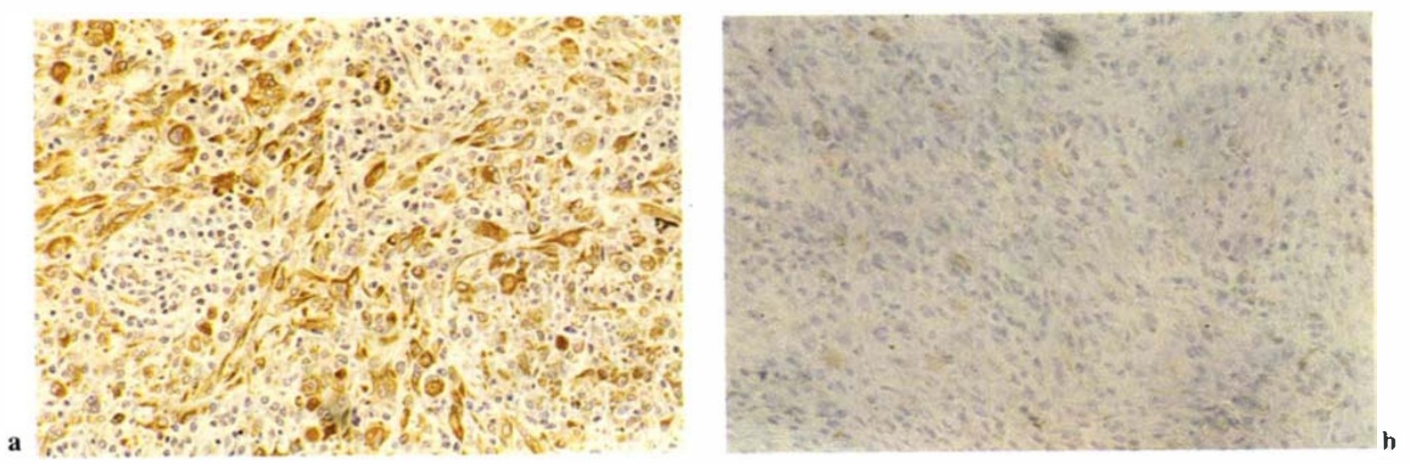

Fig. 2. Immunoperoxidase staining of tumour cells in a primary uveal melanoma. Lymphocytes and macrophages within the tumour are negative. (a) Immunoperoxidase reaction. (b) Negative control. Final magnification $\times 105$.
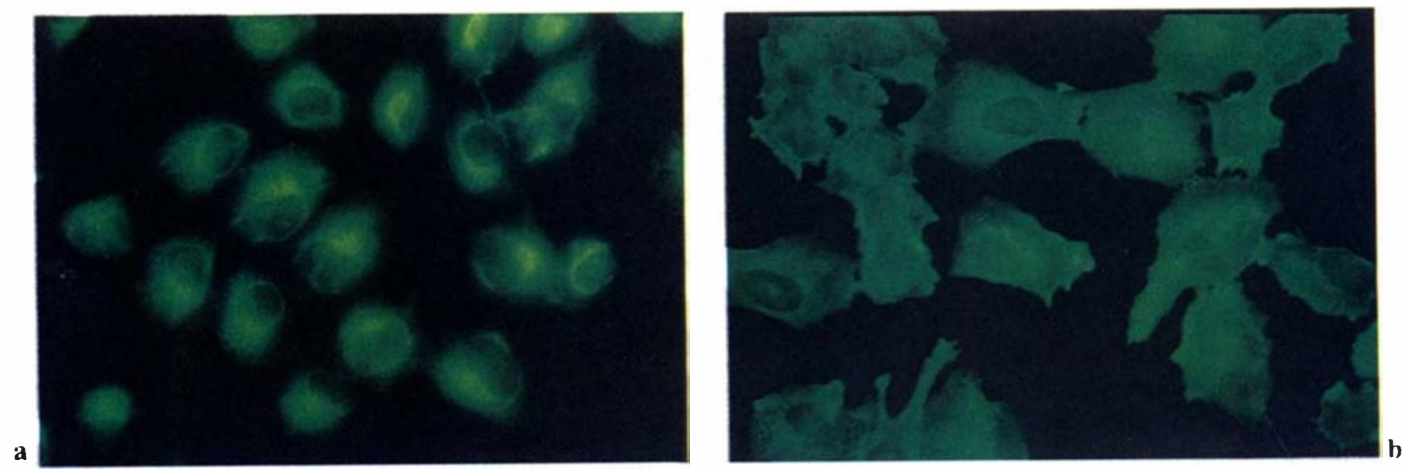

Fig. 3. Immunofluorescent staining of cultured B008 melanoma cells. (a) Monoclonal antibody $4 A 3$ detects an antigen which is concentrated in the peri-nuclear region. (b) Monoclonal antibody 4B4-2 reacts with a cytoskeletal antigen. Final magnification $\times 105$.

technique used in this study favoured the detection of intracellular rather than membrane antigens. Finally, IgM monoclonal antibodies can react with more than one specific antigen. ${ }^{14}$ For example, even if the $4 \mathrm{~A} 3$ antigen were specific for melanoma, the $4 \mathrm{~A} 3$ monoclonal antibody, being polyvalent, might nevertheless react with other tissues in a 'multispecific' fashion.

Despite being only relatively specific, monoclonal antibodies to melanoma could nevertheless be very useful in research and clinical practice. With these reagents, for example, it has been possible to correlate antigenic expression in primary cutaneous melanomas with the risk of subsequent metastatic disease. ${ }^{15}$ This approach might provide useful insights into the potential risk of metastatic disease in patients with uveal melanoma. The detection of the 4A3 antigen in subretinal fluid of patients with uveal melanoma suggests that small amounts of this and other melanoma-associated antigens might be detectable in other body fluids. Such techniques, which have already been used with cutaneous melanoma,${ }^{16}$ could be of value in diagnosing the primary tumour or in demonstrating that a patient already has metastatic disease. A number of monoclonal antibodies when administered to patients with disseminated melanoma have been shown to accumulate within tumour tissue. ${ }^{17}$ These reagents, when conjugated to radioisotopes, could be very helpful, when conventional methods fail, to establish the diagnosis of an intraocular tumour. Treatment of melanoma by targeting toxic agents with monoclonal antibodies has been attempted already with encouraging preliminary results. ${ }^{18.19}$ One of the difficulties associated with the administra- 


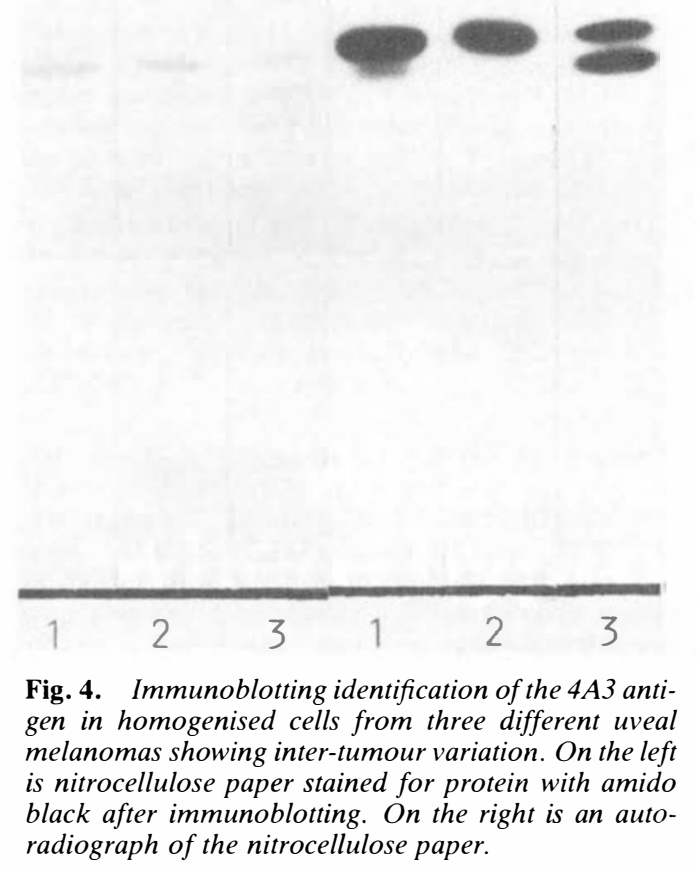

tion of agents like ricin and radioactive isotopes is damage to other organs, such as the liver and kidney, in which monoclonal antibodies tend to accumulate. This factor is less likely to cause problems with the use of photodynamic agents, which are toxic only when exposed to light. It may not be long, therefore, before monoclonal antibodies are used to enhance the accumulation of haematoporphyrin derivatives ${ }^{21}$ in uveal melanoma thereby reducing the systemic photosensitivity that currently complicates the use of such agents.

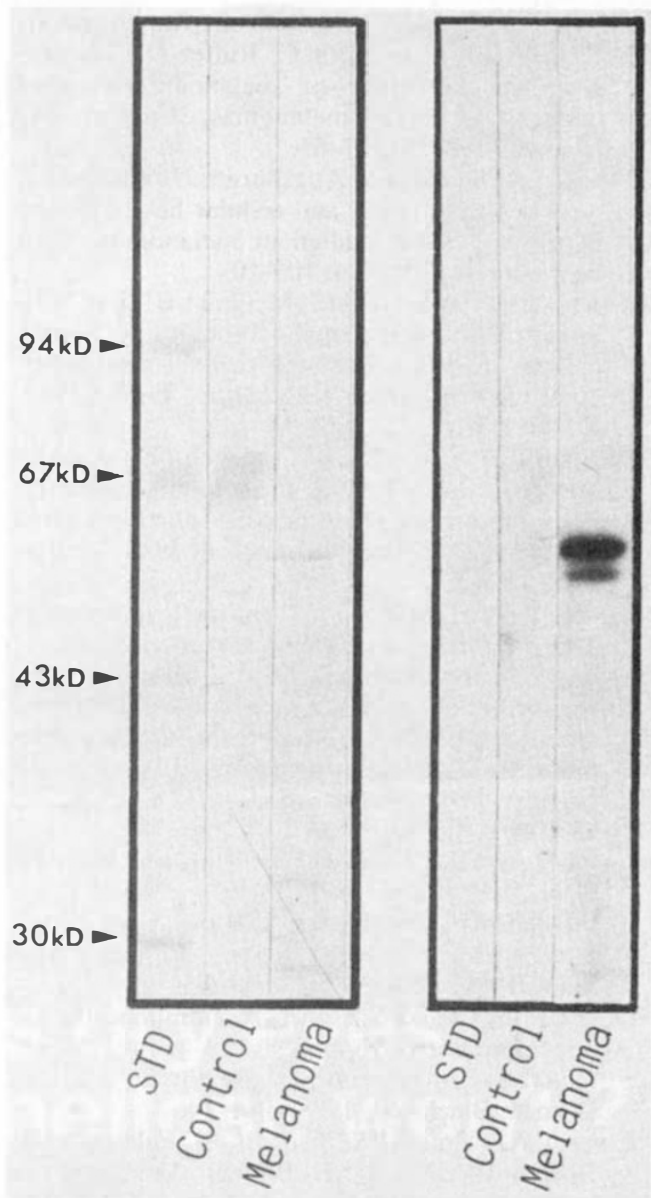

Fig. 5. Immunoblotting identification of the $4 A 3$ antigen in subretinal fluid from a patient with uveal melanoma (Melanoma) but not from a patient with rhegmatogenous retinal detachment (Control). On the left is nitrocellulose paper stained for protein with amido black after immunoblotting. On the right is an autoradiograph of the nitrocellulose paper.

After an initial phase of enthusiasm, realism has entered into the evaluation of monoclonal antibodies to tumour-associated antigens. Nevertheless, as the technology improves, there is every reason for long-term optimism that monoclonal antibodies will prove to be of value in ophthalmic oncology.

This work was supported by the Scottish Hospital Endowments Research Trust.

\section{References}

' Köhler G and Milstein C: Continuous cultures of fused cells secreting antibody of predefined specificity. Nature 1975, 256: 495-7. 
${ }^{2}$ van der Pol JP, Jager MJ, de Wolff-Rouendaal D, Ringens PJ, Vennegoor C, Ruiter DJ: Heterogeneous expression of melanoma-associated antigens in uveal melanomas. Current Eye Research 1987, 6: 757-65.

${ }^{3}$ Donoso LA, Shields JA, Augsburger JJ, Whitman J, Arbizo V: Antigenic and cellular heterogeneity of primary uveal malignant melanomas. Arch Ophthalmol 1986, 104: 106-10.

${ }^{4}$ Damato BE, Campbell AM, McGuire BJ, Lee WR, Foulds WS: Monoclonal antibodies to human primary uveal melanomas demonstrate tumor heterogeneity. Invest Ophthalmol Vis Sci 1986, 27: 1362-7.

${ }^{5}$ Douillard JY and Hoffman T: Enzyme-linked immunosorbent assay for screening monoclonal antibody production using enzyme-labelled second antibody. Methods in Enzymology 1983, 92: 16874.

${ }^{6}$ Campbell AM: Monoclonal antibody technoiogy: The production and characterization of rodent and human hybridomas, Oxford, Elsevier, 1984.

${ }^{7}$ Towbin H, Staehelin T, Gordon J: Electrophoretic transfer of proteins from polyacrylamide gels to nitrocellulose sheets: procedures and some applications. Proc Natl Acad Sci USA 1979, 76: 4350-4.

${ }^{8}$ Sternberger LA: Immunocytochemistry, 2nd edn. New York, Wiley, 1979.

${ }^{9}$ Willingham MC and Pastan I: An atlas of immunofluorescence in cultured cells. London, Academic Press 1985, pp 2-13.

${ }^{10}$ Ouchterlony Ö and Nilsson L-Å: Immunodiffusion and immunoelectrophoresis. In Weir DM ed. Handbook of experimental immunology, Ch 19, Oxford, Blackwell, 1978, pp 1-14.

${ }^{11}$ Creasey AA, Smith HS, Hackett AJ, Fukuyama K, Epstein WL, Madin SH: Biological properties of human melanoma cells in culture. In vitro 1979 15: $342-50$.

${ }^{12}$ Hersey P: Review of melanoma antigens recognized by monoclonal antibodies (MAbs). Their functional significance and applications in diagnosis and treatment of melanoma. Pathology 1985, 17: 346-54.
${ }^{13}$ Houghton AN, Cordon-Cardo C, Eisinger M: Differentiation antigens of melanoma and melanocytes. Int Rev Exp Path 1986, 28: 217-48.

${ }^{14}$ Ghosh S and Campbell AM: Multispecific monoclonal antibodies. Immunology Today 1986, 7: 21722.

${ }^{15}$ Brüggen J, Bröcker E-B, Suter L, Redmann K, Sorg $\mathrm{C}$ : The expression of tumor-associated antigens in primary and metastatic human malignant melanoma. Behr Inst Mitteil 1984, 74: 19-22.

${ }^{16}$ Ross AH, Herlyn M, Ernst CS, Guerry D, Bennicelli J, Ghrist BFD, Atkinson B, Koprowski H: Immunoassay for melanoma-associated proteoglycan in the sera of patients using monoclonal and polyclonal antibodies. Cancer Research 1984, 44: 4642-7.

${ }^{17}$ Murray JL, Rosenblum MG, Lamki L, Glenn HJ, Krizan Z, Hersh EM, Plager CE, Bartholomew RM, Unger MW, Carlo DJ: Clinical parameters related to optimal tumor localization of indium111-labeled mouse antimelanoma monoclonal antibody ZME-018. J Nuc Med 1987, 28: 25-33.

${ }^{18}$ Houghton AN, Mintzer D, Cordon-Cardo C, Welt S, Fliegel B, Vadhan S, Carswell E, Melamed MR, Oettgen HF, Old LJ: Mouse monoclonal IgG3 antibody detecting $G_{\mathrm{D} 3}$ ganglioside: $A$ phase I trial in patients with malignant melanoma. Proc Natl Acad Sci USA 1985, 82: 1242-6.

${ }^{19}$ Spitler LE, del Rio M, Khentigan A, Wedel NI, Brophy NA, Miller LL, Harkonen WS, Rosendorf LL, Lee HM, Mischak RP, Kawahata RT, Stoudemire JB, Fradkin LB, Bautista EE, Scannon PJ: Therapy of patients with malignant melanoma using a monoclonal antimelanoma antibody-ricin A chain immunotoxin. Cancer Research 1987, 47: 1717-23.

${ }^{20}$ Mew D, Wat C-K, Towers GHN, Levy G: Photoimmunotherapy: treatment of animal tumors with - tumor-specific monoclonal antibody-hematoporphyrin conjugates. J Immunol 1983, 130: 1473-7. 